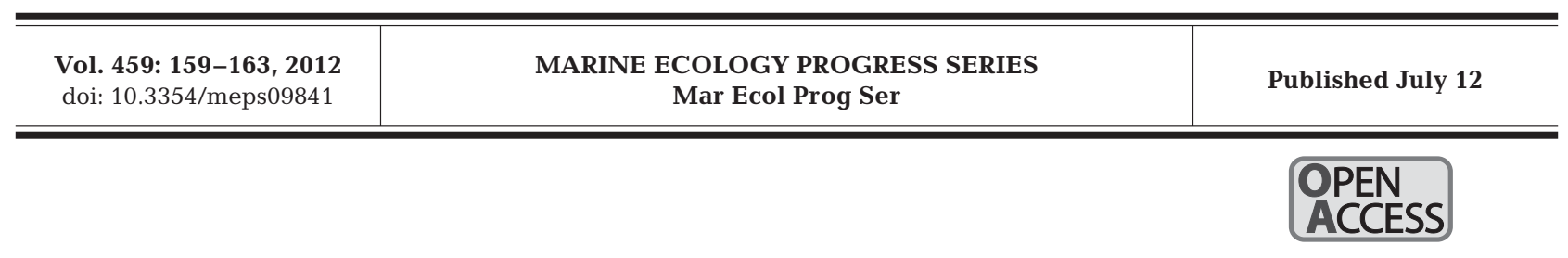

\title{
INTRODUCTION
}

\section{What drives marine fisheries production?}

\author{
Sarah K. Gaichas ${ }^{1, *}$, Alida Bundy ${ }^{2}$, Thomas J. Miller ${ }^{3}$, Erlend Moksness ${ }^{4}$, \\ Konstantinos I. Stergiou ${ }^{5}$ \\ ${ }^{1}$ National Atmospheric and Oceanic Administration, National Marine Fisheries Service, Northeast Fisheries Science Center, \\ Woods Hole, Massachusetts 02543, USA \\ ${ }^{2}$ Department of Fisheries and Oceans, Bedford Institute of Oceanography, Halifax, Nova Scotia, Canada, B2Y 14A2 \\ ${ }^{3}$ Chesapeake Biological Laboratory, University of Maryland Center for Environmental Science, Solomons, Maryland 20688, USA \\ ${ }^{4}$ Institute of Marine Research, Flødevigen Marine Research Station, 4817 His, Norway \\ ${ }^{5}$ Department of Biology, Aristotle University or Thessaloniki, Thessaloniki 54 124, Greece
}

\begin{abstract}
This paper introduces the MEPS Theme Section (TS) 'Comparative Analysis of Marine Fisheries Production'. The unifying theme of the studies in the TS is the relative influence of a 'triad of drivers' - fishing, trophodynamic, and environmental - on fisheries production. The studies were developed during 2 international workshops held in 2010 and 2011, which assembled a database of fisheries, trophodynamic, and environmental time series from 13 northern hemisphere marine ecosystems, and applied a common production-modeling approach to this data. The studies encompass empirical examinations of the datasets, production models fitted to the data at multiple levels of organization from single species to full ecosystems, and simulation studies examining the impacts of climate effects and alternative management strategies on fisheries production. The body of work presented in the TS demonstrates that using both production modeling and the comparative approach together makes rapid progress towards ecosystem-based fishery management, whether the aim is a better understanding of the ecosystem or the provision of operational management advice.
\end{abstract}

KEY WORDS: Marine fisheries · Production models $\cdot$ Comparative approach $\cdot$ Ecosystem based fishery management

Resale or republication not permitted without written consent of the publisher

\section{Ecosystem drivers of marine fisheries production}

Marine fisheries, which provide an important source of protein for human consumption worldwide (Garcia \& Rosenberg 2010), take place within the larger context of marine ecosystems. The sustainability of fisheries resources is inextricably linked with the sustainability of ecosystem processes (Sherman 1994, Pikitch et al. 2004, Link 2010). Therefore, understanding the linkages between ecosystem processes and fisheries production is critical to the effec- tive management of marine fisheries resources. The unifying theme for the MEPS Theme Section (TS) 'Comparative analysis of marine fisheries production' is that ecosystem processes can be organized into a 'triad of drivers': (1) exploitative, (2) biophysical, and (3) trophodynamic, supporting fisheries production (See Fig. 1 in Link et al. 2012, this TS). What, however, is the extent to which each of these drivers control fisheries production across marine ecosystems? To address this question in the TS, we adopted a comparative approach using a standardized productionmodeling framework. 


\section{Production modeling for a comparative approach}

Many multispecies or ecosystem models have been developed over the last few decades, and several reviews are available (e.g. Plagányi 2007, Townsend et al. 2008). They range from extended single species models to multispecies minimum realistic models, and from food web models to whole ecosystem models with age and spatial structure. All models have strengths and weaknesses: simplicity may entail missing key processes, whereas complexity requires more data, time and resources. For a comparative exercise such as this, production models (also called biomass-dynamics models) were selected because of their simple data requirements and the flexibility to apply them at different scales of space, time and species aggregation.

Production models have a long history of use in ecology and fisheries science (Graham 1935, Schaefer 1954, Pella \& Tomlinson 1969, Ricker 1975, Hilborn \& Walters 1992). Although many current single species stock assessments used to advise fisheries managers employ more complex age-structured population dynamics models, the simple production model can provide important information for ecosystem-based fisheries management $(E B F M$; see e.g. Browman \& Stergiou 2004, 2005, Link 2010). Production models require only the basic data inputs of catch and biomass, and so are applicable for incidentally caught, relatively data-poor non-target species as well as data-rich commercial target species. Production models can be applied at multiple levels of organization, from single species to functional groups to ecosystems, simply by summing the appropriate biomass and catch time series. Importantly, biological reference points (BRPs) currently used for fisheries management, such as maximum sustainable yield (MSY), can be derived directly from production models. Therefore, production models are capable of providing BRPs for non-target species, for functional groups, and for whole ecosystems; BRPs that are not estimable from the age-structured single species stock assessment models applied to commercial target species.

The simplicity of the production-modeling approach, combined with the general availability of necessary input data, forms an ideal framework for comparative analysis of marine ecosystems. The comparative approach to ecosystem analysis is an effective way to examine the underlying drivers of ecosystem structure and productivity, given that direct marine ecosystem-scale experimentation is usually impractical, and replicate experimentation near impossible (Murawski et al. 2010). Previous work on marine ecosystems of the northeast Pacific, northwest Atlantic and northeast Atlantic demonstrates the power of the comparative approach for revealing common trends as well as structural differences critical to both ecosystem understanding and management (Drinkwater et al. 2009, Gaichas et al. 2009, Link et al. 2009, Megrey et al. 2009a,b, Mueter et al. 2009). In this MEPS TS, we extend this work, using the standardized production-modeling framework, which allows for direct comparisons of BRPs and other model-derived quantities of interest across ecosystems.

\section{Workshops}

Two international workshops focusing on annual surplus production-modeling were held in May of 2010 and 2011 in Woods Hole, Massachusetts, USA (Link et al. 2010). These workshops, jointly funded by the US Comparative Analysis of Marine Ecosystem Organization (CAMEO), the Norwegian Research Council (NRC), and the Fishery and Oceans Canada Ecosystem Research Initiative (ERI), extended previous comparative work, including many of the same ecosystems (Megrey et al. 2009c), but with focus on the common surplus production-modeling framework. Our late colleague and friend Bernard Megrey was instrumental in developing the productionmodeling approach for these workshops, in fostering the international collaboration, and in enthusiastically promoting the comparative approach to marine ecosystem analysis. We dedicate the TS to him (Moksness et al. 2012).

At the May 2010 workshop, biomass and catch time series data were compiled for 13 Northern Hemisphere ecosystems ranging from the northeast Pacific to the northwest and northeast Atlantic (See Fig. 2 in Link et al. 2012; see also Fu et al. 2012, their Table 1, and Bundy et al. 2012, their Tables 1 \& A1). In addition, time series for environmental covariates (e.g. sea surface temperature, the North Atlantic Oscillation), and trophodynamic covariates (e.g. primary production, predator biomass, diet matrices) were assembled for each ecosystem (Bundy et al. 2012, their Tables 2 \& A2, Fu et al. 2012, their Table 2). The standardized database built for this project during the first workshop provided the foundation for the comparative analyses presented in this TS. The database, with over 70000 records and including 466 biological and 162 environmental time series across the 13 ecosystems, is itself a significant contribution to EBFM. At the workshop, experts from each ecosys- 
tem identified key environmental covariates and mechanisms for testing, and also assigned species to appropriate aggregate groups (e.g. pelagic vs. benthic feeder, large vs. small size category) for crosssystem comparisons. Standardization and quality control of the database was completed simultaneously with initial production model development between workshops.

During the May 2011 workshop, several working groups applied the production models to the data from all of the ecosystems: working groups focused on comparing ecosystems by evaluating empirical data, single species production models, full ecosystem production models, and production models applied at intermediate aggregation levels for habitat, size, feeding functional group, and taxonomic categories. Comparisons were primarily across ecosystems, but also among modeling approaches, aggregation methods, driver types (i.e. fishing, biophysical, trophodynamic) and driver scales (i.e. basin, local).

\section{Results}

The comparative modeling and empirical work conducted by workshop attendees and presented in this TS identify emergent trends and common patterns governing fishery productivity in northern hemisphere temperate marine ecosystems. Two papers examine the rich time series data assembled in the database empirically (Fu et al. 2012, Pranovi et al. 2012). Using multivariate approaches, Fu et al. (2012) compared temporal variability in ecosystem indicators derived from biomass or catch data across the ecosystems, finding that catch-based indicators showed consistent trends primarily within ocean basins. Structural equation modeling related the triad of drivers to both biomass- and catch-based ecosystem indicators, revealing that biophysical drivers tended to influence biomass-based indicators, exploitative drivers influenced catch-based indicators, and that trophodynamic drivers had some influence across both biomass- and catch-based indicators (Fu et al. 2012). A potential new ecosystem indicator is presented by Pranovi et al. (2012) who examine cumulative biomass curves by trophic level and their changes through time in all of the ecosystems. Changes in the inflection point and slope of the curves may be used as indicators of community status, with some ecosystems showing trophic stability over time, and others substantial structural changes (Pranovi et al. 2012).
Three studies presented in this TS fit production models to the data from as many of the 13 ecosystems as possible, at various levels of aggregation (Bundy et al. 2012, Holsman et al. 2012, Lucey et al. 2012). All compared a production-modeling approach (i.e. a simple linear regression and/or a dynamic model) with a null model of constant surplus production. Holsman et al. (2012) applied models at the single species level of organization, comparing both cod and herring production across ecosystems. Lucey et al. (2012) applied models at intermediate levels of organization, including habitat-based groups (i.e. demersal and pelagic), size-based groups (i.e. small, medium, and large average adult size), and trophic functional groups (i.e. planktivores, zoopivores - shrimp-feeders, piscivores, and benthivores). Bundy et al. (2012) applied models at the full system level. In nearly all cases, a production-modeling approach provided better fits to the data than the null model across all levels of aggregation. A striking result of all 3 studies was the general similarity of estimated BRPs across ecosystems at each level of organization, a result highlighted in a synthesis paper (Link et al. 2012). Two of these studies also explored whether including system-specific environmental covariates would improve model fits; their results support the hypothesis that environmental covariates affect fisheries production at both the single species and full ecosystem levels (Bundy et al. 2012, Holsman et al. 2012).

Four other contributions focus on fisheries production and management implications, either in particular regions or at a larger scale. Two papers use simulation modeling to address the influence of the triad of drivers on BRPs in 1 or 2 representative ecosystems (Gaichas et al. 2012, Gamble \& Link 2012), and 1 study compares the results of fitted production models at the system and single species level within a single ecosystem, the Gulf of Maine (Fogarty et al. 2012). Finally, a synthesis paper examines the implications for EBFM across all of the studies (Link et al. 2012). Simulation modeling was conducted using MS-PROD, a multispecies production model incorporating both competitive and predatory species interactions (Gamble \& Link 2009). Gaichas et al. (2012) used MS-PROD, parameterized for two 10-species communities based on Georges Bank and the Gulf of Alaska, as an operating model within a management strategy evaluation (MSE) framework to determine how best to structure aggregate species complexes to achieve the dual objectives of maximizing yield and maintaining biodiversity. Gamble \& Link (2012) parameterized MS-PROD for the wider northeast US continental shelf ecosystem, to examine the potential 
effects of climate change on BRPs. Moving from simulation to model fitting for operational management advice, Fogarty et al. (2012) used the Gulf of Maine ecosystem as a case study comparing the results of a system-level aggregate production model with a set of single species production models, as well as the results of single species stock assessments. That study, as well as the overall synthesis, reiterates that the sum of single species BRPs exceeds any aggregate BRP for the ecosystem (Fogarty et al. 2012, Link et al. 2012), an important overall finding for EBFM.

In summary, the body of work presented in this TS demonstrates that using both production modeling and the comparative approach together makes valuable and rapid progress towards EBFM, whether the aim is a better understanding of the ecosystem, or the provision of operational management advice. The breadth and depth of analyses presented here (which were achieved within a 2-yr timeframe) highlight the utility of relatively simple models combined with long-term time series maintained by the participating international institutions. This body of work also highlights the benefits of collaborative projects where the total profit to be gained is much greater than the sum of the parts (contrasting with findings reported here that multispecies MSY is generally less than the sum of single species MSYs). We expect that this approach will be useful in other areas of the world, especially where data may be limiting but EBFM is equally as important.

Acknowledgements. This collaborative, multilateral work was funded through the US Comparative Analysis of Marine Ecosystem Organization (CAMEO), the Norwegian Research Council (NRC), and the Fishery and Oceans Canada Ecosystem Research Initiative (ERI). Major national institutes (the Canada Department of Fisheries and Oceans, Norway Institute for Marine Research, and US National Marine Fisheries Service) also contributed significant 'in-kind' and directed resources to this project. This work is endorsed by the Ecosystem Studies of Subarctic Seas (ESSAS) program. The work we report upon herein resulted from several joint meetings, particularly the Surplus Production Modeling Workshop (SPMW 1 \& 2) and associated inter-sessional efforts, representing a continuation of and follow-on to other joint workshops, including Canadian and US Ecosystems (CANUSE I \& II), Marine Ecosystems of Norway and the US (MENU I \& II), and Norwegian-Canadian Collaborations (NORCAN).

\section{LITERATURE CITED}

Browman HI, Stergiou K (eds) (2004) Perspectives on ecosystem-based approaches to the management of marine resources. Mar Ecol Prog Ser 274:269-303

Browman HI, Stergiou K (eds) (2005) Politics and socio- economics of ecosystem-based management of marine resources. Mar Ecol Prog Ser 300:241-296

Bundy A, Bohaboy EC, Hjermann DO, Mueter FJ, Fu C, Link JS (2012) Common patterns, common drivers: comparative analysis of aggregate surplus production across ecosystems. Mar Ecol Prog Ser 459:203-218

> Drinkwater K, Mueter FJ, Friedland KD, Taylor M, Hunt GL, Hare JA, Melle W (2009) Recent climate forcing and physical oceanographic changes in Northern Hemisphere regions: a review and comparison of four marine ecosystems. Prog Oceanogr 81:10-28

Fogarty MJ, Overholtz WJ, Link JS (2012) Aggregate surplus production models for demersal fishery resources of the Gulf of Maine. Mar Ecol Prog Ser 459:247-258

$>$ Fu C, Gaichas S, Link JS, Bundy A and others (2012) Relative importance of fisheries, trophodynamic and environmental drivers in a series of marine ecosystems. Mar Ecol Prog Ser 459:169-184

Gaichas S, Skaret G, Falk-Petersen J, Link JS and others (2009) A comparison of community and trophic structure in five marine ecosystems based on energy budgets and system metrics. Prog Oceanogr 81:47-62

> Gaichas S, Gamble R, Fogarty M, Benoît H and others (2012) Assembly rules for aggregate-species production models: simulations in support of management strategy evaluation. Mar Ecol Prog Ser 459:275-292

Gamble RJ, Link JS (2009) Analyzing the tradeoffs among ecological and fishing effects on an example fish community: a multispecies (fisheries) production model. Ecol Model 220:2570-2582

Gamble RJ, Link JS (2012) Using an aggregate production fisheries simulation model with ecological interactions to explore effects of fishing and climate on a fish community. Mar Ecol Prog Ser 459:259-274

Garcia SM, Rosenberg AA (2010) Food security and marine capture fisheries: characteristics, trends, drivers and future perspectives. Philos Trans R Soc Biol Sci 365: 2869-2880

Graham M (1935) Modern theory of exploiting a fishery and application to North Sea trawling. J Cons Int Explor Mer 10:264-274

Hilborn R, Walters CJ (1992) Quantitative fisheries stock assessment: choice, dynamics, and uncertainty. Chapman \& Hall, New York, NY

> Holsman KK, Essington T, Miller TJ, Koen-Alonso M, Stockhausen WJ (2012) Comparative analysis of cod and herring production dynamics across 13 northern hemisphere marine ecosystems. Mar Ecol Prog Ser 459:231-246

Link JS (2010) Ecosystem-based fisheries management: confronting tradeoffs. Cambridge University Press, Cambridge

Link JS, Stockhausen WT, Skaret G, Overholtz WJ and others (2009) A comparison of biological trends of four marine ecosystems: synchronies, differences and commonalities. Prog Oceanogr 81:29-46

$>$ Link JS, Megrey BA, Miller TJ, Essington TE and others (2010) Comparative analysis of marine ecosystems: International Production Modeling Workshop. Biol Lett 6: 723-726

> Link JS, Gaichas S, Miller TJ, Essington T and others (2012) Synthesizing lessons learned from comparing fisheries production in 13 northern hemisphere ecosystems: emergent fundamental features. Mar Ecol Prog Ser 459: 293-302

> Lucey SM, Cook AM, Boldt JL, Link JS, Essington TE, Miller 
TJ (2012) Comparative analyses of surplus production dynamics of functional feeding groups across 12 northern hemisphere marine ecosystems. Mar Ecol Prog Ser 459:219-229

Megrey BA, Hare JA, Stockhausen WT, Dommasnes A and others (2009a) A cross-ecosystem comparison of spatial and temporal patterns of covariation in recruitment of functionally analogous fish stocks. Prog Oceanogr 81: 63-92

> Megrey BA, Link JS, Hunt GL, Moksness E (2009b) Comparative marine ecosystem analysis: applications, opportunities, and lessons learned. Prog Oceanogr 81:2-9

Megrey BA, Link JS, Moksness E (2009c) Comparative marine ecosystem structure and function: descriptors and characteristics. Prog Oceanogr 81:1

Moksness E, Link J, Drinkwater K, Gaichas S (2012) Bernard Megrey: pioneer of Comparative Marine Ecosystem analyses. Mar Ecol Prog Ser 459:165-167

Mueter FJ, Broms C, Drinkwater KF, Friedland KD and others (2009) Ecosystem responses to recent oceanographic variability in high-latitude Northern Hemisphere ecosystems. Prog Oceanogr 81:93-110

Murawski SA, Steele JH, Taylor P, Fogarty MJ, Sissenwine MP, Ford M, Suchman C (2010) Why compare marine ecosystems? ICES J Mar Sci 67:1-9

Pella JJ, Tomlinson PK (1969) A generalized stock production model. Bull I-ATCC 13:419-496

> Pikitch EK, Santora C, Babcock EA, Bakun A and others (2004) Ecosystem-based fishery management. Science 305:346-347

Plagányi ÉE (2007) Models for an ecosystem approach to fisheries. Fisheries Technical Paper, Vol 477. FAO, Rome

> Pranovi F, Link J, Fu C, Cook AM and others (2012) Trophic level determinants of biomass accumulation in marine ecosystems. Mar Ecol Prog Ser 459:185-201

Ricker WE (1975) Computation and interpretation of biological statistics of fish populations, Vol 191. Department of Environment, Fisheries and Marine Service, Ottawa

Schaefer MB (1954) Some aspects of the dynamics of populations important to the management of commercial marine fisheries. Bull I-ATCC 12:27-56

Sherman K (1994) Sustainability, biomass yields, and health of coastal ecosystems: an ecological perspective. Mar Ecol Prog Ser 112:277-301

Townsend HM, Link JS, Osgood KE, Gedamke T and others (2008) Report of the National Ecosystem Modeling Workshop (NEMoW). US Dept of Commerce, NOAA Tech Memo NMFS-F/SPO-87 